\title{
Caution over use of catheter ablation for atrial fibrillation
}

A tagging error meant that the first subheading of the table in this Analysis article by Van Brabandt and colleagues (BMJ 2013;347:f5277, doi:10.1136/bmj.f5277) did not appear. The subheading should have been before the first study (Wazni,
2005) and should have read "Studies recruiting patients with paroxysmal $\mathrm{AF} \dagger . "$

Cite this as: BMJ 2013;347:f5688

๑ BMJ Publishing Group Ltd 2013 